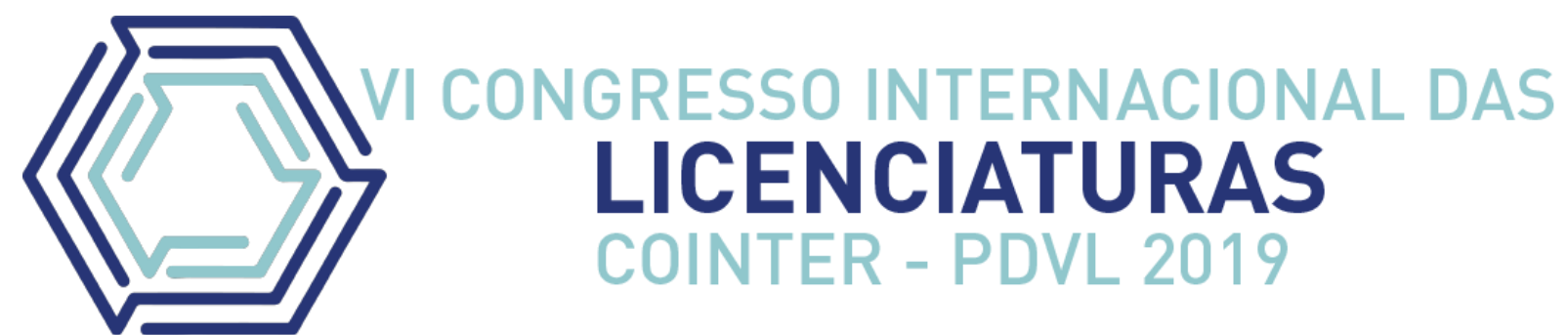

\title{
A IMPORTÂNCIA DOS JOGOS DIDÁTICOS E A LUDICIDADE DO ENSINO DE CIÊNCIAS ATRAVÉS DO PIBID
}

\section{LA IMPORTANCIA DE LOS JUEGOS DE ENSEÑANZA Y LA LUDICIDAD DE LA ENSEÑANZA DE CIENCIAS A TRAVÉS DEL PIBID}

\section{THE IMPORTANCE OF TEACHING GAMES AND THE LUDICITY OF SCIENCE TEACHING THROUGH PIBID}

Apresentação: Comunicação Oral

\begin{abstract}
Alípio Henrique Guimarães Leal ${ }^{1}$; Juliana Frazão Bezerra ${ }^{2}$; Alessandra de Araújo Silva ${ }^{3}$, Aretuza Bezerra Brito Ramos ${ }^{4}$
\end{abstract}

DOI: https://doi.org/10.31692/2358-9728.VICOINTERPDVL.2019.0104

\begin{abstract}
Resumo
Este trabalho se propôs a analisar a importância que o lúdico e os jogos didáticos exercem no contexto do ensino de ciências, assim, a utilização dos jogos, dos brinquedos e das brincadeiras como forma de educar, é um grande avanço para a educação. Quando bem orientado, o jogo pode ser um excelente recurso para o ensino aprendizagem. Por isso, é importante ressaltar que "pensar é brincar com a imaginação. Escrever é brincar com as palavras. Tudo é possível quando solta a cabeça e deixa voar o coração..." Diante das dificuldades encontradas nas escolas, mostra que é preciso modificar o processo de ensino no contexto escolar onde o aluno possa ter curiosidade em aprender o conteúdo de uma forma mais prática e prazerosa, onde esse método possa conduzir o aluno a viver o imaginário inesperado, descobrir o que existe além da sala de aula, do quadro de giz, livros didático e dos termos científicos propostos pelas monótonas aulas de ciências. O lúdico traz um grande leque de oportunidade a ser explorado pelo educador como o caráter da dinâmica, a interação e a socialização dos alunos, com isso, resgatam-se as brincadeiras introduzindo-os no contexto pedagógico da escola. Desta forma, o presente estudo utilizou uma abordagem qualitativa descritiva e exploratória, no qual se fez uso da pesquisa de campo, buscando alcançar os objetivos propostos. Os resultados mostram que a utilização de ferramentas se fez essencial para a aprendizagem do estudante, onde se faz perceptível a interação e a participação dos alunos, instigando a curiosidade dos mesmos. Utilizar-se dessa metodologia é promover ao educando uma aprendizagem significativa que favorece a aquisição de conhecimentos sobre os conceitos propostos. Contudo, as escolas ainda precisam desfazer as dificuldades que existem em compreender este instrumento facilitador essencial, no entanto, muitas ainda priorizam o método tradicional de ensino. Embora, os professores precisam ter consciência da importância das atividades lúdicas para o desenvolvimento e do processo de ensino aprendizagem.
\end{abstract}

\footnotetext{
${ }^{1}$ Ciências Biológicas, AEDS FACHUSC, alipioleal14@gmail.com

${ }^{2}$ Ciências Biológicas, AEDS FACHUSC, jullyf.2@hotmail.com

3 Pedagogia, FACHUSC, sandraegabi203@hotmail.com

${ }^{4}$ Mestre em Gestão e Políticas Ambientais, FACHUSC, brito.ramos.ab@gmail.com
} 
Palavras-Chave: Lúdico, Aprendizagem e Ensino.

\title{
Resumen
}

El objetivo de este trabajo es analizar la importancia que los juegos lúdicos y didácticos ejercen en el contexto de la enseñanza de las ciencias, por lo tanto, el uso de los juegos, los juguetes y los juegos como forma de educación es un gran avance para la educación. Cuando está bien dirigido, el juego puede ser un excelente recurso para enseñar a aprender. Por lo tanto, es importante enfatizar que "pensar es jugar con la imaginación. Escribir es jugar con palabras. Cualquier cosa es posible cuando dejas ir tu cabeza y dejas volar tu corazón ..." Dadas las dificultades encontradas en las escuelas, muestra que es necesario modificar el proceso de enseñanza en el contexto escolar donde el estudiante puede sentir curiosidad por aprender contenido de una manera más práctica. y placentero, donde este método puede llevar al estudiante a vivir el imaginario inesperado, descubrir lo que existe más allá del aula, la pizarra, los libros de texto y los términos científicos propuestos por las clases de ciencias monótonas. Lo lúdico brinda una amplia gama de oportunidades para que el educador las explore como el personaje de la dinámica, la interacción y la socialización de los estudiantes, rescatando así los juegos introduciéndolos en el contexto pedagógico de la escuela. Por lo tanto, el presente estudio utilizó un enfoque cualitativo descriptivo y exploratorio, que hizo uso de la investigación de campo, buscando alcanzar los objetivos propuestos. Los resultados muestran que el uso de herramientas fue esencial para el aprendizaje de los estudiantes, donde se nota la interacción y participación de los estudiantes, despertando su curiosidad. El uso de esta metodología es para promover al alumno un aprendizaje significativo que favorezca la adquisición de conocimiento sobre los conceptos propuestos. Sin embargo, las escuelas aún necesitan deshacer las dificultades que existen para comprender este instrumento facilitador esencial, aunque muchas aún priorizan el método de enseñanza tradicional. Sin embargo, los maestros deben ser conscientes de la importancia de las actividades lúdicas para el proceso de desarrollo y enseñanza-aprendizaje.

Palabras Clave: Juguetón, aprendiendo y enseñando.

\begin{abstract}
This paper aims to analyze the importance that the playful and the didactic games exert in the context of the science teaching, thus, the use of the games, the toys and the games as a way of educating, is a great advance for the education. When well targeted, the game can be an excellent resource for teaching learning. Therefore, it is important to emphasize that "thinking is playing with the imagination. Writing is playing with words. Anything is possible when you let your head go and let your heart fly ..." Given the difficulties encountered in schools, it shows that it is necessary to modify the teaching process in the school context where the student may be curious to learn content in a more practical way. and pleasurable, where this method can lead the student to live the unexpected imaginary, discover what exists beyond the classroom, the chalk board, textbooks and the scientific terms proposed by the monotonous science classes. The playful brings a wide range of opportunity to be explored by the educator as the character of the dynamics, interaction and socialization of students, thus rescuing the games by introducing them in the pedagogical context of the school. Thus, the present study used a descriptive and exploratory qualitative approach, which made use of field research, seeking to achieve the proposed objectives. The results show that the use of tools was essential for student
\end{abstract}


learning, where it is noticeable the interaction and participation of students, arousing their curiosity. Using this methodology is to promote the student a significant learning that favors the acquisition of knowledge about the proposed concepts. However, schools still need to undo the difficulties that exist in understanding this essential facilitating instrument, yet many still prioritize the traditional teaching method. However, teachers need to be aware of the importance of playful activities for the development and teaching-learning process.

Keywords: Leisure, Learning and Teaching

\section{Introdução}

O Programa Institucional de Bolsas de Iniciação à Docência (PIBID) é uma ação do governo federal que busca valorizar os cursos de licenciatura, sendo em 2007instituída pelo Ministério da Educação e cultura, com responsabilidade da Coordenação de Aperfeiçoamento Pessoal de Nível Superior (CAPES). Segundo a Portaria n 096, de 18 de julho de 2013, o Pibid tem por finalidade fomentar a iniciação à docência, contribuindo para o aperfeiçoamento, da formação do discente em nível superior, e para melhoria da educação básica pública brasileira (CAPES. 2019).

De acordo com Programa, deve-se promover a iniciação do licenciando no ambiente escolar ainda na primeira metade do curso, visando estimular desde o início de sua formação, a observação e a reflexão sobre a prática profissional no cotidiano das escolas públicas de educação básica (CAPES. 2019).

De acordo com a CAPES (2019), o Pibid é um programa que veio para desenvolver projetos com parcerias entre autarquias e instituições federais dentro das escolas estaduais. Dando oportunidades para os discentes em formação de um conceito de aperfeiçoamento na prática para iniciação a docente.

Diferente do seu termo de origem, o lúdico passou a ser conhecido como traço essencial psicofisiológico, ou seja, uma necessidade básica fundamental para o desenvolvimento e aprendizado dos alunos que estão no processo de despertar e aprender a ciências de uma forma lúdica (SILVA. 2011).

Destarte, as atividades lúdicas no ensino fundamental vêm despertando maior interesse com práticas privilegiadas para aplicação dentro da escola que visam despertar o desenvolvimento pessoal do aluno e a atuação e cooperação do contexto escolar, aonde o lúdico vem como principal instrumento que motiva, atrai e estimula o processo de construção do conhecimento educativo (SOARES, 2014).

Desta forma, o objetivo desse trabalho foi buscar conhecer e entender as dificuldades 
encontradas nas escolas, onde mostra que é preciso modificar o processo de ensino no contexto escolar no qual o aluno possa ter a curiosidade em aprender o conteúdo de uma forma mais prática e prazerosa, onde este método possa conduzir o aluno a viver o imaginário inesperado, descobrir o que existe além da sala de aula, do quadro de giz, livros didáticos e dos termos científicos propostos pelas monótonas aulas de ciências. Há também dificuldades especificamente na execução da ferramenta lúdica no contexto disciplinar diante das dificuldades que os professores têm em administrar a prática lúdica em sala de aula.

\section{Fundamentação Teórica}

\section{Lúdico}

A palavra lúdica se origina do latim ludus que significa brincar, onde se pode expressar a concepção do lúdico e do seu uso como ferramenta metodológica na formação de professores para que venha aperfeiçoar sua prática nas aulas de ciências. O lúdico é brincadeira onde o jogo leva o estudante a compreender e aprender de uma forma mais divertida, para que através deste método o aprendizado de ciências se torne mais atrativo e divertido. (CORBALÁN. 1994)

Ressalta-se que, o brincar se faz presente desde a antiguidade mantendo-se notório até os dias atuais. Pode-se afirmar que para cada época e sociedade a concepção sobre a educação sempre teve um entendimento diferenciado. Desde a antiguidade, Platão já apontava a importância da utilização de jogos para que o aprendizado pudesse ser desenvolvido e conceituado de uma forma positiva no desenvolvimento das crianças (VYGOTSKY, 2003).

Almeida (2009) enfatiza que durante a atividade lúdica o que importa é a ação e o momento que ele proporciona tais como levar o aluno a viver o imaginário buscando o prazer de aprender o conteúdo de uma forma espontânea.

\section{Importância do lúdico no contexto escolar}

Vygotsky (2003), O lúdico traz um grande leque de oportunidade a ser explorado pelo educador como o caráter da dinâmica, a interação e a socialização dos alunos, com isso resgatase as brincadeiras introduzindo no contexto pedagógico da escola. O lúdico influencia o desenvolvimento do aluno ensinando-o a agir corretamente em uma determinada situação, estimulando sua capacidade de disseminar. Os jovens possuem um papel relevante no processo de aprendizagem fazendo os alunos adquirir iniciativa e alto confiança no processo de aprendizagem. 
De acordo com mesmo autor, a influência por meio dos jogos, consegue desenvolver no aluno o cognitivo sendo livre para determinar suas próprias ações, onde o jogo vai estimular a curiosidade e conseguintemente levando o aluno a aprender de uma forma mais prática.

Assim, a utilização dos jogos, dos brinquedos e das brincadeiras como forma de educar é um grande avanço para a educação. Quando bem orientado, o jogo pode ser um excelente recurso para o ensino aprendizagem. Por isso, é importante ressaltar que "pensar é brincar com a imaginação. Escrever é brincar com as palavras. Tudo é possível quando solta a cabeça e deixa voar o coração...” (TELLES, 1998, p28).

Nos últimos anos, com a ampla divulgação das ideias de práticas construtivas os recursos pedagógicos são crescentes nas escolas, mas a quantidade não garante a qualidade (CUNHA, 2001). De acordo com Souza (2019), a escola deve enfatizar no jogo as situações problemas, os desafios e conflitos. Com essas práticas em sala de aula a criança sente intrínseca para aprimorar sua inteligência e capacidade em aprender.

O uso adequado das ferramentas didáticas empoe resultados positivos nos objetivos que o professor deseja alcançar, com isso, é importante afirmar e direcionar para qual realidade está voltado, como aplicar as dinâmicas unificando a ludicidade com o conteúdo proposto. $\mathrm{O}$ ato de brincar proporciona a construção do conhecimento de forma natural e agradável para as crianças (CUNHA, 2001, p.14).

É nesse sentido que se deve observar com mais atenção o que os educadores pretendem ensinar aos educandos, para que, através de jogos e brincadeiras, eles possam desenvolver um potencial de conhecimento em sua formação escolar (KISHIMOTO, 2002).

Conforme o autor Kishimoto (2002), o lúdico possibilita ao educador conhecer-se como pessoa, saber suas possibilidades, desbloquear a resistência em aplicar dinâmicas lúdicas e ter uma visão clara sobre a importância do jogo e do brinquedo para a vida da criança, do jovem e do adulto.

Entretanto, diante do processo educativo como está posto, o educador percebe-se imerso em um universo dinâmico em constante transformação, no qual o ato de educar se modifica a todo o momento. Professor bom não é aquele que dá uma aula perfeita, explicando o conteúdo; professor bom é aquele que transforma o conhecimento, a ser aprendido, em uma dinâmica produtiva e seduz o aluno a desenvolver-se na prática da ludicidade (VIDAL, 2001).

Segundo Rizzi (2002), uma aula com características lúdicas não precisa ter jogos ou 
brinquedos na sua concepção. O que traz a ludicidade para a sala de aula, é muito mais uma atitude lúdica do educador e dos educandos. Essa postura do educando possibilita um leque de oportunidades e conhecimento no que diz respeito ao aprendizado do aluno.

\section{Metodologia}

O presente trabalho é uma ação desenvolvida pelos bolsistas do Programa Institucional de Bolsas de Iniciação à Docência da Faculdade de Ciências Humanas do Sertão Central, que foi desenvolvida de setembro de 2018 a maio de 2019.

A proposta metodológica foi constituída em duas etapas. A primeira etapa deu-se a partir da observação e ambientação no universo escolar, e a segunda foi desenvolvida através da intervenção e construção de jogos como práticas formativas na disciplina de ciências do ensino fundamental. Desta forma, o presente estudo utilizou uma abordagem qualitativa descritiva e exploratória, no qual se fez uso da pesquisa de campo, buscando alcançar os objetivos propostos.

A primeira etapa proporcionou conhecer as estratégias pedagógicas desenvolvidas pelos professores com base nas experiências vivenciadas pelos alunos em sala do ensino fundamental, cuja finalidade foi pesquisar e refletir sobre a importância do lúdico no desenvolvimento cognitivo dessas crianças.

A pesquisa foi realizada no município de Salgueiro/PE localizado a $508 \mathrm{~km}$ da capital Recife, especificamente na escola Professora Maurina Rodrigues dos Santos, que conta com 451 alunos entre o $6^{\circ}$ e $9^{\circ}$ do ensino fundamental, e 13 funcionários que estão distribuídos entre a direção, coordenador, secretaria, bibliotecária, merendeiras, auxiliares de serviços gerais, porteiros, e 20 vinte professores das mais variadas áreas de formação.

Diante da observação do espaço escolar foi possível realizar uma avaliação em um contexto geral. Mas, para recolher mais informações e dados em relação ao funcionamento da instituição foi elaborada uma entrevista com a equipe de gestão, além de pessoas encarregadas de outras áreas da mecânica e da metodologia pedagógica. As perguntas foram relacionadas à avaliação escolar, plano pedagógico, funcionamento do SIEPE, merenda escolar, relacionamento entre gestão e alunos e estrutura da escola.

$\mathrm{Na}$ segunda etapa foram propostas dinâmicas lúdicas para serem desenvolvidas junto com o professor de ciências. Com o intuito de melhorar o desempenho dos educandos, foi escolhida apenas uma turma para se desenvolver tais ferramentas, sendo desenvolvidas duas ferramentas lúdicas, uma para cada bimestre letivo. Salienta-se que, essas atividades foram 
escolhidas de acordo com a necessidade e a dificuldade que os alunos estariam tendo para aprender e fixar o conteúdo.

\section{Resultados e Discussão}

\section{Observação e Ambientação}

O período de ambientação ocorreu de outubro a dezembro de 2018, onde foi possível realizar anotações do espaço escolar do contexto pedagógico.

No que se referem ao corpo docente da escola, as entrevistas mostram que a relação entre funcionário e aluno é excelente da mesma forma que a relação entre funcionários e gestores, existe boa relação entre ambos. É indispensável que o gestor educacional por meio de uma gestão participativa tenha o desafio de promover mudanças pedagógicas que garantam a qualificação e uma boa relação ofertada visando atingir metas estabelecidas construindo a identidade da escola e respeitando a identidade dos indivíduos que delas fazem parte (RIOS, 2003). A coordenadora de apoio pedagógico da escola exerce a sua respectiva função cumprindo com total desempenho e profissionalismo, assim como, os demais funcionários.

De acordo com Veiga (1995), para a construção de projetos políticos pedagógicos na escola, não é necessário convencer os professores, a equipe escolar e os funcionários a trabalhar mais, ou mobilizá-los de forma espontânea, mas propiciar situações que permitam aprender a pensar e a realizar o fazer pedagógico de forma coerente.

Quanto à estrutura escolar, haveria alterações como, por exemplo, adotarem novas janelas para que seja possível a luz natural entre na sala de aula, auxiliando na iluminação do ambiente, assim agregando também ventilação, que é um problema a ser considerado para que seja possivelmente solucionado. Embora que as janelas atuais sejam consideravelmente grandes, não se faz suficiente para épocas quentes, assim a adoção de novos ventiladores pode com facilidade solucionar essa irregularidade.

Desta forma, através das dificuldades encontradas, foi proposta para a gestão escolar uma tabela de sugestões de melhorias que pudessem vir a aprimorar a qualidade dos espaços observados. 
Tabela 1: Sugestões de melhorias da infraestrutura da Escola Professora Maurina Rodrigues dos Santos em Salgueiro/PE.

\begin{tabular}{|c|c|c|c|}
\hline $\begin{array}{c}\text { Demandas } \\
\text { Identificadas }\end{array}$ & Sugestões & Responsáveis & $\begin{array}{l}\text { Meios para } \\
\text { Atendimento }\end{array}$ \\
\hline Ventiladores & $\begin{array}{lr}\text { Manutenção } \\
\text { dos } & \text { equipamentos } \\
\text { disponíveis. }\end{array}$ & $\begin{array}{l}\text { Professores } \\
\text { Estudantes } \\
\text { Gestão. }\end{array}$ & $\begin{array}{lcc}\text { Organizar } & \text { rifas } \\
\text { ou } & \text { bingo } & \text { para } \\
\text { manutenção } & \\
& \text { Convidar } & \text { pais } \\
\text { como voluntários para a } \\
\text { manutenção. }\end{array}$ \\
\hline $\begin{array}{l}\text { Melhor } \\
\text { aproveitamento do } \\
\text { ambiente externo }\end{array}$ & \begin{tabular}{l}
\multicolumn{3}{c}{ Realizar } \\
aulas que \\
dinamizem r os \\
espaços, usando do \\
lúdico, no ensino das \\
ciências.
\end{tabular} & $\begin{array}{l}\text { Gestão e } \\
\text { Professores de } \\
\text { Ciências. }\end{array}$ & $\begin{array}{l}\text { Utilização } \\
\text { desses espaços externos } \\
\text { para aulas dinâmicas. }\end{array}$ \\
\hline $\begin{array}{l}\text { Equipamentos } \\
\text { laboratoriais em } \\
\text { desuso, para reativar } \\
\text { um laboratório } \\
\text { básico. }\end{array}$ & $\begin{array}{lr} & \text { Utilizar uma } \\
\text { sala em desuso, para } \\
\text { a montagem } & \text { desse } \\
\text { espaço, } & \text { assim, } \\
\text { montando } & \text { um } \\
\text { laboratório } & \text { básico } \\
\text { para as } & \text { aulas } \\
\text { práticas de ciências. }\end{array}$ & $\begin{array}{l}\text { Gestão e } \\
\text { professores de } \\
\text { Ciências. }\end{array}$ & $\begin{array}{l}\text { Retirar os } \\
\text { materiais do "depósito" } \\
\text { e designar para suas } \\
\text { finalidades, } \\
\text { aproveitando o máximo } \\
\text { os materiais presentes na } \\
\text { escola. Organizar um } \\
\text { mutirão dos estagiários } \\
\text { para a montagem do } \\
\text { laboratório, listando os } \\
\text { itens que estão em falta, } \\
\text { ou mesmo, os itens que } \\
\text { podem ser utilizados } \\
\text { para cada assunto } \\
\text { didático. }\end{array}$ \\
\hline $\begin{array}{l}\text { Uso mais } \\
\text { frequente da } \\
\text { biblioteca }\end{array}$ & $\begin{array}{l}\text { Organização } \\
\text { do espaço e dos } \\
\text { livros, com auxílio } \\
\text { dos estagiários. }\end{array}$ & $\begin{array}{l}\text { Gestão } \\
\text { escolar e } \\
\text { bibliotecária. }\end{array}$ & $\begin{array}{l}\text { Disponibilidade } \\
\text { mais frequente da } \\
\text { bibliotecária. }\end{array}$ \\
\hline $\begin{array}{l}\text { Incentivo ao } \\
\text { uso dos lixeiros } \\
\text { coloridos na coleta } \\
\text { seletiva }\end{array}$ & \begin{tabular}{l}
\multicolumn{3}{c}{ Produzir } \\
placas para os \\
diferentes tipos de \\
lixeiras e incentivar \\
os alunos ao \\
descarte do lixo no \\
local correto, através \\
de palestras de \\
conscientização.
\end{tabular} & $\begin{array}{l}\text { Gestão, } \\
\text { professores, alunos e } \\
\text { estagiários. }\end{array}$ & \begin{tabular}{lrr} 
& \multicolumn{3}{c}{ Conversar } & com \\
a gestão & e & os \\
professores, sobre & a \\
organização & & das \\
palestras e as melhorias \\
da coleta seletiva na \\
escola.
\end{tabular} \\
\hline
\end{tabular}

Fonte: Própria (2019)

De acordo com Davis (1993), o espaço físico escolar é de suma importância para um bom desenvolvimento do aluno, pois é lá que eles passam parte de sua vida presente neste ambiente e não apenas para serem educados, mas para se comunicar e socializar com as demais pessoas ao seu redor, uma boa estrutura escolar é fundamental para se obter um bom rendimento. 
Corroborando com Moran (2000), existem duas razões para se investir na estrutura da escola, a primeira trata das condições físicas de trabalho em que diz respeito ao meio do corpo docente disponível para um trabalho mais produtivo, mais prazeroso, e menos desgastante para o educador. A segunda razão, quando se fala de educação um trabalho de importância inegável, afinal melhor infraestrutura está relacionada com melhor qualidade de ensino.

A escola, foco de ação deste estudo, possui uma estrutura de qualidade, onde as salas são bem arejadas, mais com poucos ventiladores, alguns em bom estados, e outros parados, a mesma possui um espaço amplo, onde poderia ser mais explorados pelos alunos, em termo de aulas práticas, com relação a merenda, é de qualidade, onde é feito acompanhamento mensalmente pelas nutricionistas, que prestam serviço ao estado de Pernambuco.

Desta forma, foi relatado através da gestora que é a principal portadora e responsável pela merenda escolar, onde recebe os alimentos através de cotas solicitadas pela secretaria de educação do estado estas cotas totalizam de 10 que são distribuídas ao longo do ano, no ano de 2018, foram divididas as 10 em duas cotas. O cardápio da merenda é repassado através da nutricionista que presta serviço ao estado e que manda mensalmente a lista do cardápio distribuída no mês ou a cada 06 meses. Onde este cardápio é repassado às merendeiras onde elas fazem a distribuição das merendas a serem feitas para os alunos.

A alimentação escolar pode comprovadamente exercer influência positiva no rendimento escolar, uma vez que aumenta a capacidade de concentração dos alunos nas atividades escolares. (BARBOSA, 2004).

Após a etapa de ambientação e observação, iniciou-se o período de intervenção com ferramentas lúdica nas aulas de ciências, onde só foi possível após as observações feita na primeira etapa do programa. Em seguida, no primeiro bimestre foi ministrada a primeira dinâmica, o Jogo da Memória Celular, já no segundo bimestre a ferramenta utilizada foi o PlayDoh do Sistema Urinário, ressaltando que, estes foram os conteúdos em que os alunos tiveram mais dificuldade na aprendizagem

\section{Jogo da Memória Celular}

Bibiano (2010) afirma que a origem do jogo da memória veio do antigo Egito. Na china utilizavam essas técnicas para o desenvolvimento do raciocínio e memorização. $\mathrm{O}$ jogo tem como objetivo a memorização das imagens de forma rápida, desenvolvendo e aperfeiçoando o raciocínio, podendo desenvolver outras habilidades como: discriminação visual, atenção e a 
concentração.

Ao dar início à atividade lúdica do jogo da memória na turma no $8^{\circ}$ ano, foi apresentado aos alunos às células, variações de tipos de células, e os principais tipos de tecidos auxilio de maquete, explicando a função de cada organela que a compõem.

Logo após a explicação, iniciou-se o jogo apresentando placas com imagens de estruturas, onde eles teriam que identificar cada imagem e a função de cada uma delas. A turma foi dividida em duplas, à medida que as placas eram viradas, a equipe que responder corretamente e obtiver o maior número de acerto venceria o jogo. Foram utilizados um total de 20 placas com imagens e as funções de cada uma como mostram a tabela 3. O jogo teve a duração de 1 hora e 30 minutos no decorrer de três horas aula.

Os materiais utilizados para a confecção da ferramenta foram materiais simples e de fácil acesso, podendo ser replicado por qualquer professor que deseja fazer de sua aula mais lúdica, prática e atrativa para o desenvolvimento da aprendizagem do estudante.

Tabela 3: Modelo das placas da dinâmica utilizada na Escola Professora Maurina Rodrigues dos Santos em Salgueiro/PE.

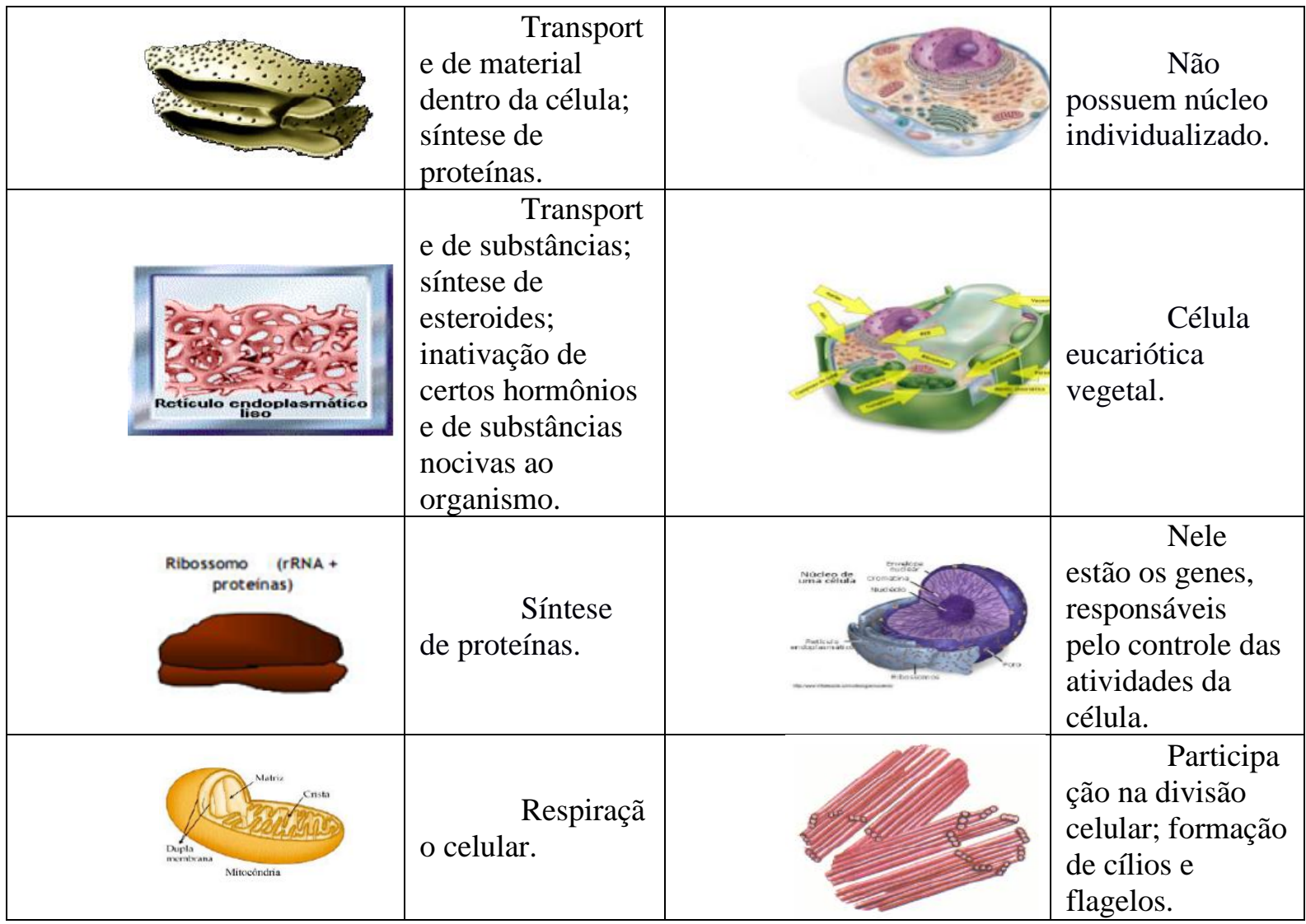




\begin{tabular}{|c|c|c|c|}
\hline 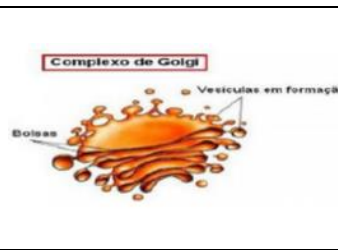 & $\begin{array}{l}\quad \text { Acúmulo } \\
\text { e eliminação de } \\
\text { secreções; } \\
\text { proteicas; síntese } \\
\text { de carboidratos. }\end{array}$ & $\begin{array}{l}\text { MEN'BRANA PLA ŚTATICA } \\
\text { TRANSPORTES }\end{array}$ & $\begin{array}{l}\quad \text { Fina } \\
\text { película que } \\
\text { controla a } \\
\text { entrada e a saída } \\
\text { de substâncias. }\end{array}$ \\
\hline 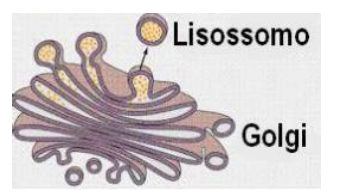 & $\begin{array}{l}\text { Digestão } \\
\text { intracelular. }\end{array}$ & & $\begin{array}{l}\quad \text { Protege e } \\
\text { sustenta a célula } \\
\text { vegetal. }\end{array}$ \\
\hline ats 1 & \begin{tabular}{l}
\multicolumn{1}{c}{ Contêm } \\
enzimas que \\
promovem a \\
reação do \\
oxigênio com \\
algumas \\
moléculas \\
orgânicas.
\end{tabular} & 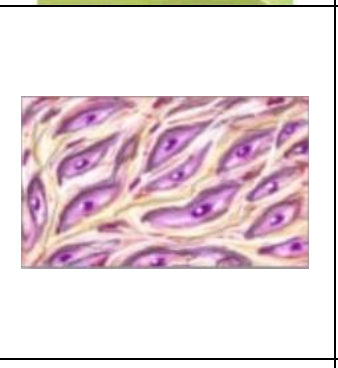 & $\begin{array}{l}\text { Tecido } \\
\text { conjuntivo tem } \\
\text { como função a } \\
\text { sustentação. }\end{array}$ \\
\hline & $\begin{array}{l}\quad \text { Capacida } \\
\text { de de a célula } \\
\text { vegetal conter } \\
\text { maior ou menor } \\
\text { quantidade de } \\
\text { água }\end{array}$ & & $\begin{array}{l}\qquad \text { Tecido } \\
\text { epitelial tem } \\
\text { como função } \\
\text { revestir o corpo } \\
\text { humano. }\end{array}$ \\
\hline Cloropasto & $\begin{array}{ll} & \text { Fotossínt } \\
\text { ese. } & \end{array}$ & & $\begin{array}{l}\text { Tecido } \\
\text { muscular tem } \\
\text { como função } \\
\text { contração. }\end{array}$ \\
\hline & $\begin{array}{l}\text { Não } \\
\text { possuem núcleo } \\
\text { individualizado. }\end{array}$ & & \begin{tabular}{l}
\multicolumn{1}{c}{ Tecido } \\
nervoso tem \\
como função de \\
captar estímulos \\
ambientais ou do \\
próprio corpo, \\
conduzir \\
impulsos \\
nervosos e \\
interpretá-los, na \\
coordenação das \\
funções dos \\
órgãos.
\end{tabular} \\
\hline
\end{tabular}

Fonte: Própria (2019)

Este jogo teve como finalidade instigar curiosidade dos alunos buscando entender o conteúdo onde se faz uma revisão das principais funções constituintes das células. Segundo Ferreira (2010), utilizar-se desta metodologia é promover aos educandos uma aprendizagem significativa que favorece a aquisição de conhecimento sobre os conceitos de células e suas estruturas, possibilitando ao aluno a curiosidade em buscar mais conhecimento que possa favorecer seu aprendizado. 
Após a execução da dinâmica, foi realizada uma avaliação oral administrada pela professora de ciências, onde os resultados mostraram que a utilização da ferramenta lúdica se fez essencial para o aprendizado do estudante. As fotos da figura 1 mostram a interação e a participação dos alunos instigando a curiosidade dos mesmos.

Figura 1: Apresentação jogo da memória celular na Escola Professora Maurina Rodrigues dos Santos em Salgueiro/PE.

Demonstração das maquetes utilizadas.

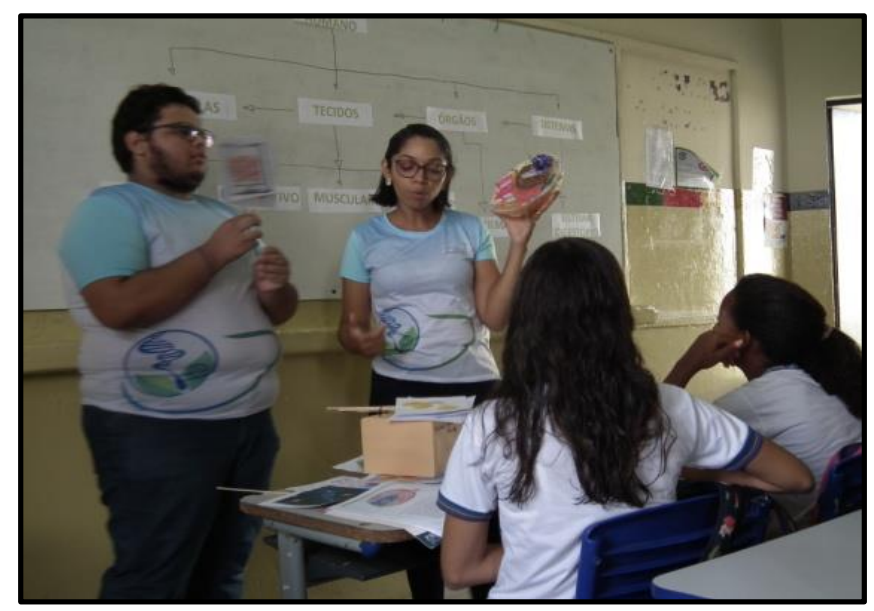

Fonte: Própria (2019)

\section{Play-Doh do Sistema Urinário}

A princípio com início da segunda ferramenta didática abordando os conceitos trabalhados sobre sistema urinário nas aulas de ciências, a dinâmica pedagogia foi introduzida para os alunos com um vídeo simples e prático explicando todo o funcionamento do sistema urinário e as estruturas. Após o término do vídeo deu-se início a atividade lúdica onde foi distribuído um total de oito kits para a confecção da maquete e de suporte eles tiveram uma imagem de referência para auxiliá-los na produção do sistema. Assim foi possível dar início a construção e identificação de cada estrutura no tempo estimado de 60 minutos, venceria o grupo que conseguisse fazer todas as etapas da dinâmica e ao fim teria uma premiação para as duas primeiras duplas que conseguisse desenvolver todo o processo da ferramenta corretamente.

A utilização da massa de modelar no processo de ensino-aprendizagem do tema proposto contribuiu para a facilitação da compreensão dos alunos em entender os processos do sistema urinário, viabilizando uma maior interação entre os estudantes.

Foi utilizada massa de modelar, isopor, palitos de dente, fichas com os nomes de cada estrutura e cola de isopor. Através destes materiais distribuídos para os grupos, foi possível a confecção de réplicas do sistema urinário utilizando a massa de modelar, onde cada estudante 
do grupo formado designou uma função para a construção da maquete, possibilitando a troca de conhecimento (Figura 2).

De acordo com Ferreira (2010) as atividades lúdicas têm o intuito de aproximar o aluno da teoria e a prática associando a realidade de seus conhecimentos empíricos com os conceitos científicos, e através destes jogos educativos é possível despertar o interesse, mostrando que é capaz aprender ciências de uma forma prática e lúdica.

Zanon (2007) ainda coloca que o debate em grupos promove o desenvolvimento das habilidades de ouvir, onde se pode chegar a um consenso, respeitar a opinião de cada indivíduo. Todas essas habilidades têm sido cada vez mais aprimoradas em diferentes disciplinas. Dessa forma, o ensino em diversas áreas na educação também contribui para a formação de futuro profissional.

Figura 2: Execução da segunda ferramenta lúdica na Escola Professora Maurina Rodrigues dos Santos. As imagens a seguir mostram o desenvolvimento da ferramenta em sala, onde na figura (A) mostra todo o material utilizado na dinâmica; nas figuras (B) o momento da explicação de como seria desenvolvida a ferramenta; as figuras $(\mathrm{C}$ e D) acompanhamento do procedimento correto do desenvolvimento; (E) a primeira dupla a finalizar corretamente todo o processo e (F) conclusão de todas as maquetes confeccionadas.

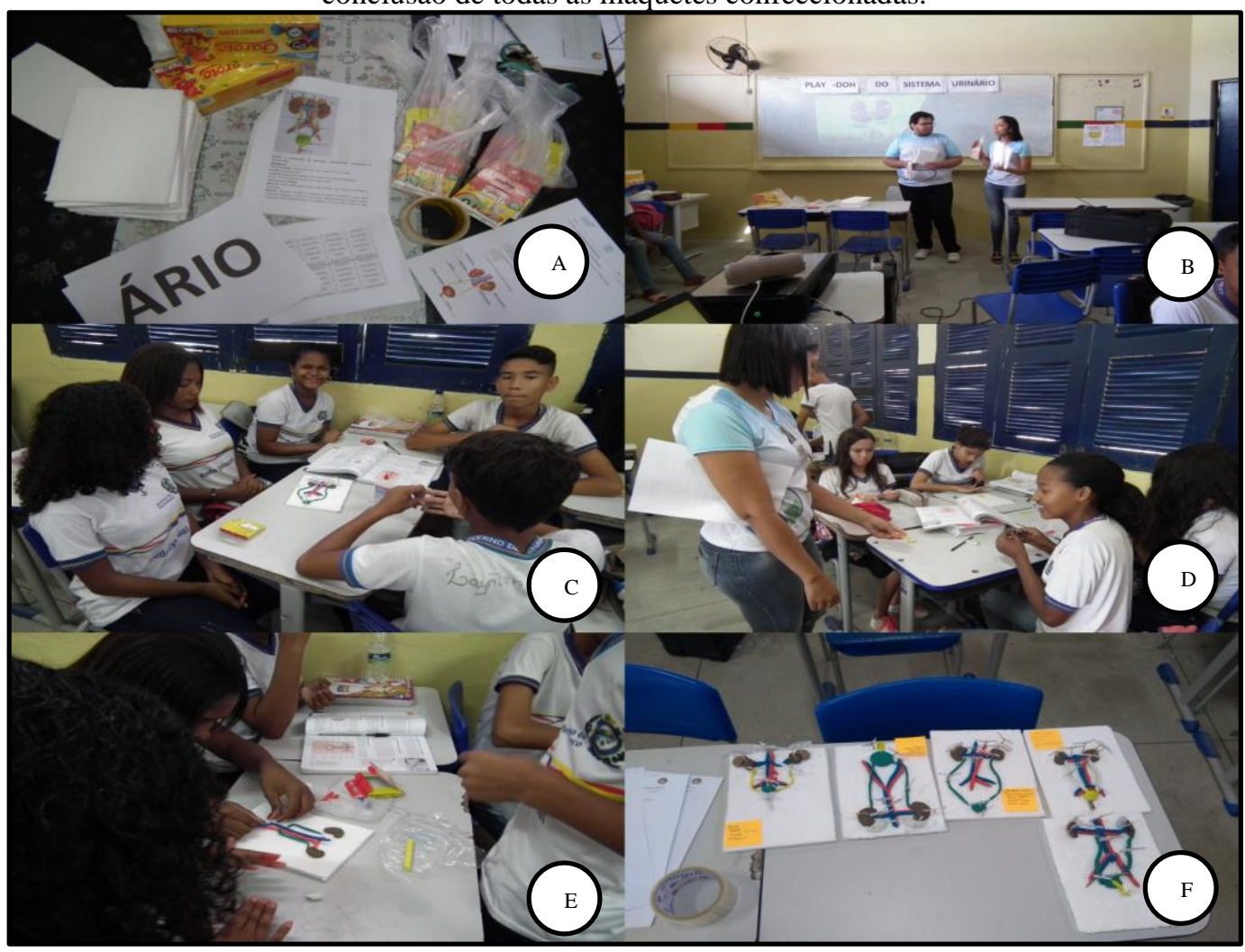

Fonte: Própria (2019) 
Desta forma, este foi o método utilizado para avaliar os alunos e testar seus conhecimentos com relação ao conteúdo trabalhado e concluir se a dinâmica realmente foi positiva para o aprendizado. Com o relato da professora de ciências mostrou que mais de $70 \%$ dos alunos conseguiram resultados positivos.

De acordo com Rossini (2011), compreende-se a importância das formas alternativas que a atividade lúdica pode favorecer para o ensino de ciências e é de grande relevância para motivar os alunos. O lúdico pode levar o aluno a se interessar mais pelo aprendizado se ele for trabalhado de maneira prazerosa.

\section{Conclusões}

É importante considerar que a utilização de jogos pedagógicos integra o lúdico ao conteúdo, auxiliando na educação formal e informal e com a utilização de jogos pedagógicos, podem potencializar o desejo de exploração e construção de um conhecimento, tornando possível por motivação interna típica da ferramenta lúdica

Conclui-se que o lúdico no contexto dos jogos pedagógicos no ensino de ciências torna uma aula mais agradável e dinâmica motivando os alunos a participarem ativamente da construção do próprio conhecimento trazendo mudanças significativas ao aluno. O lúdico é uma das ferramentas de melhor apoio para ser desenvolvido em sala de aula, trazendo para o contexto de sala a importância do aprender brincando e com isso transmitindo o conhecimento.

Contudo, as escolas ainda precisam desfazer as dificuldades que existem em compreender este instrumento facilitador essencial, no entanto, muitas ainda priorizam o método tradicional de ensino. Embora, os professores precisam ter consciência da importância das atividades lúdicas para o desenvolvimento e do processo de ensino aprendizagem.

\section{Referências}

ALMEIDA, A. Ludicidade como instrumento pedagógico. Cooperativa fitness, Belo Horizonte, jan. 2009. Seção Publicação de Trabalhos Disponível em: http://www.cdof.com.br/recrear22.htm. Acesso em 11 jan. 2019.

BARBOSA, V. L. P. Prevenção da obesidade na infância e na adolescência: exercício, nutrição e psicologia. Barueri (SP): Manole, 2004.

BIBIANO, B. Jogo da Memória. Disponível em http://revistaescola.abril.com.br/educacaoinfantil/4-a-6-anos/jogo-memoria-613022.shtml. Acessado em 11 jul. 2019. 
CAPES, Coordenação de Aperfeiçoamento de Pessoas de Nível Superior. Programa Institucional de Bolsas à Docência. Disponível em http://www.capes.gov.br/educacaobasica/capespibid. Acesso em 08 jul. 2019.

CORBALÁN, F. Juegos matemáticos para secundaria y bachillerato. Madrid: Sintesis, 1994.

CUNHA, M. H. S. Brinquedoteca: Um mergulho no brincar. 3. Ed São Paulo: Vetor 2001

DAVIS, C. O. Psicologia na educação. São Paulo: Cortez, 1993.

FERREIRA, V. Educação Física. Recreação, Jogos e desportos. Rio de Janeiro: 3 edição. Spirit, 2010.

KISHIMOTO, T. M. Jogos Infantis: O jogo, a criança e a educação. 6 Ed Petrópolis, RJ: Vozes, 2002

MORAN, J. M. M. Novas tecnologias e medidas pedagógicas. São Paulo: Papirus editora, 2000.

RIOS, T. A. Compreender e Ensinar: por uma docência de melhor qualidade. 4. Ed. São Paulo: Cortez, 2003.

ROSSINI, D. C. G.; Confecção de material pedagógico como instrumento no ensino do sistema respiratório na disciplina de ciências. In: ENCONTRO MARINGAENSE DE BIOLOGIA, 13, 2011, Maringá. Universidade Estadual de Maringá, 2011.

RIZZI, L.; HAYDT, R. C. C. Atividade Lúdicas na Educação da Criança. $7^{a}$ Ed. São Paulo: Ática, 2002.

SARTORI, J. Formação de professore: Conexões entre saberes da universidade e fazeres na educação básica, 2011.

SILVA, A. G. da. Concepção de lúdico dos professores de Educação Física infantil. Universidade estadual de londrina. Londrina: SC, 2011.

SOARES, M. Castelhano. O ensino de ciências por meio da ludicidade: alternativas pedagógicas para uma prática interdisciplinar. Revista Ciências \& Ideias VOL. 5, N.1. JAN/ABR -2014.

SOUZA, E. R. O lúdico como possibilidade de inclusão no Ensino Fundamental. Revista de Educação Física, Esporte e Lazer.

TELLES, C. Q. Palavra puxa palavra. São Paulo: Scipione, 1998

TEIXEIRA, S. R. O. de Jogos, brinquedos, brincadeira e brinquedoteca: implicações no processo de aprendizagem e desenvolvimento. /Sirlândia Reis de Oliveira Teixeira -2. Ed. RJ: Wak Editora,2012. 
VEIGA, I. P. A.; CARVALHO, M. H. S. O. A formação de profissionais da educação. In: MEC. Subsídios para uma proposta integral à criança em sua dimensão pedagógica. Brasília, 1995

VIDAL, F. F. Uma sala de aula em que se pode brincar. In: DALLA ZEN, Mª Isabel. (org.) Cadernos Educação Básica: Projetos Pedagógicos: cenas de sala de aula. Porto Alegre: Medição, 2001, n. 7, p. 36-61.

VYGOTSKY, L. S. O papel do brinquedo no desenvolvimento. In: A formação social da mente. Martins Fontes. São Paulo, 2003.

ZANON, L. B. (Org.) et al. Fundamentos e propostas de ensino de Química para a Educação Básica no Brasil. Ijuí: Unijuí, 2007.

TEIXEIRA, S. R. O. Jogos, brinquedos, brincadeira e brinquedoteca: implicações no processo de aprendizagem e desenvolvimento/Sirlândia Reis de Oliveira Teixeira -2. Ed. RJ: Wak Editora,2012. 